\title{
Twenty Minutes of Ultraviolet-B Light Improved Quality of Cherry Fruits (Prunus avium L. cv 0900 Ziraat) During Storage
}

\author{
Tuğçe Şahin ${ }^{1, a}$, Rezzan Kasım ${ }^{2, b}$, Mehmet Ufuk Kasım, ${ }^{2, *}$ \\ ${ }^{1}$ Graduate School of Natural and Applied Sciences, Kocaeli University, 41001 Kocaeli, Turkey \\ ${ }^{2}$ Faculty of Agriculture and Natural Sciences, Kocaeli University, 41285 Kocaeli, Turkey
}

*Corresponding author

\section{A R T I C L E I N F O A B S T R A C T}

Research Article

This study was carried out to determine the effects of ultraviolet-B (UV-B) and LED light on improving postharvest quality of 0900 Ziraat cherry fruits. In the present study, UV-B treated to cherry fruits 10,20 , and $40 \mathrm{~min}$, and then stored dark conditions. On the other hand, the blue (M), red (KR) and ultraviolet-A (UVA) LED light had applied to fruit during storage, continuously. Fruits without application were used as a control. Cherry fruits were stored at $4 \pm 1{ }^{\circ} \mathrm{C}$ temperature with $85-90 \%$ RH for 35 days. As a result of the study, the best treatment in terms of increasing the TSS/TA rate (19.3), fructose $(5.27 \%)$, glucose $(6.22 \%)$, total soluble phenol $(170.16 \mathrm{mg} / 100 \mathrm{~mL}$ $\mathrm{CAE})$ and anthocyanin content $(12.11 \mathrm{mg} / \mathrm{kg} \mathrm{FW})$, red color, and taste quality (4.63) of fruits was UVB20. It has also been seen that the KR treatment could be used to reducing the titratable acidity content, and increase the amount of fructose, total soluble phenol. The UV-A LED treatment is

Keywords: particularly significant in reducing weight loss, and providing in the fruit stalk remains green. Also,

Cherry

Prunus avium L. cv. 0900 Ziraat UV-B the treatments of both UVB and LED improved the color quality of cherries by increasing

LED brightness, darkening red color, and protection of anthocyanins, whereas increased the EL. As a result, it might be concluded that the UVB20 $\left(5.95 \mathrm{~kJ} / \mathrm{m}^{2} \mathrm{~s}\right)$ treatment was the best and usable treatment to maintaining both biochemical and taste quality cherry fruits during cold storage.

\section{Introduction}

Cherry (Prunus avium L.), which belongs to the Rosaceae family, and is one of the important fruit species in Turkey, is structurally in the category of stone fruit species (Quero-García et al., 2017). Cherry fruits mostly consumed fresh; It used less frequently in jam, marmalade, canned food, and fruit juice production compared to other fruits. The chemical structure of cherry fruit varied by factors such as light, temperature, irrigation, fertilization, soil structure, ripening time, relative humidity, and rootstocks (Özçağıran et al., 2011). However, it generally contains $82.25 \mathrm{~g} / 100 \mathrm{~g}$ water, $16.01 \mathrm{~g} / 100 \mathrm{~g}$ carbohydrate, $1.06 \mathrm{~g} / 100 \mathrm{~g}$ protein whereas its fat content $(0.20 \mathrm{~g} / 100 \mathrm{~g})$ is very low. Cherry is also rich in vitamin C $(7 \mathrm{mg} / 100 \mathrm{~g})$ and potassium $(222 \mathrm{mg} / 100 \mathrm{~g})$ (USDA, 2020).

The total cherry production in the World is 2547944 tons with the highest production by Europe and followed by the continents of Asia, America, Africa, and Oceania. According to FAOSTAT (2020), Turkey has the first position in cherry production (639 564 tons per year).
Because Turkey has different ecologic regions and different cherry varieties that early and late-maturing, the cherry production period lasting from the beginning of May to mid-July in the country (Özçağıran et al., 2011). Due to the favorable ecological conditions, cherry production made in almost all regions of the country, but the Aegean Region is in the first place (TUIK, 2020).

LED (light-emitting diode) lighting technique first used in the United States between 1980 and 1990 for the growth of lettuce, potato, spinach, and wheat plants. The effectiveness of LED light varies due to the different wavelengths of the colors used. Although the wavelength of the LED lamps varies between 240 and $4000 \mathrm{~nm}$., in general, red and blue LED lights have higher energy. Unlike ultraviolet radiation, LED lights also have advantages such as not damaging the product, creating heat in the environment, providing electrical brightness, providing strong light emission in monochrome, high 
photon efficiency, different effectiveness of LED lights in different colors and long working time (Spotts et al., 2017).

LED technology was used primarily in greenhouse plants to increase the photosynthesis rate with chlorophyll and lycopene content in the fruit, and thus the product quality (Çakırer et al., 2017). However, in recent years, it has been used for increasing the color quality of fruits and vegetables, rising of compounds ascorbic acid, total soluble phenols, anthocyanins, flavonoids, ensuring fruit ripening, and also for surface disinfection (Kasım and Kasım, 2017b).

Due to the detrimental effects of chemicals used in surface disinfection of fruits and vegetables on human health, efforts made to find alternatives to chemicals. UV irradiation is one of the methods used for this purpose. This treatment both provides surface disinfection and also it stimulated the defense mechanism of the product via creating abiotic stress conditions, so the quality of the product could also be increased (Pala and Toklucu, 2010) Although the number of studies about UV-C among UV rays is quite much because of the shorter wavelength and more effective on microorganisms, whereas studies on UV-B and UV-A radiation are more limited (Ribeiro et al., 2012).

LED lighting technology is also a method that has been using to increase the quality of the products after harvest in recent years, and it has been found that lighting with white, red, and green LEDs in lettuce is effective in extending the storage life (Kasım and Kasım, 2017a).

As cherry is perishable fruit, thus it must be carefully harvested.The most significant quality losses of the cherry fruit during postharvest are the color changes of the fruits, the browning of the stem depends on senescence and water loss. Thus, the present study intended to investigate the effect of both the UV-B and blue, red, and ultraviolet-A LED light on the sensory and biochemical quality of cherry (cv. 0900 Ziraat) fruits during postharvest storage.

\section{Material and Methods}

\section{Plant Material}

Cherry fruits (Prunus avium L. cv. 0900 Ziraat) which were grown in the Çivril district of Denizli Province in Turkey were used as plant material, in this study.

\section{UV-B Application Device and Treatments}

The tool is in the form of a wooden bench and has three stainless steel reflectors, and lamps that provide ultraviolet B light (TL $40 \mathrm{~W} / 12 \mathrm{RS}$ Philips, Holland). The UV-B device was operated for a minimum of 15 minutes before treatment to stabilize the luminous efficacy of the lamps. Cherries have placed under this device, with a $30 \mathrm{~cm}$ distance between them, and applied to cherries in two directions. UV-B treatment was carried out in the warehouse with a temperature of $4 \pm 1^{\circ} \mathrm{C}$ to prevent the effect of the heat emitted from the lamp. The light intensity created by UV-B lamps on the cherry was measured using a radiometer (Kasım and Kasım, 2015). Treatments used were; UVB10: UVB light applied to cherries before packaging as bilaterally at a dose of $2.97 \mathrm{~kJ} / \mathrm{m}^{2}$ for 10 minutes. UVB20: UVB light applied to cherries before packaging as bilaterally at a dose of $5.95 \mathrm{~kJ} / \mathrm{m}^{2}$ for 20 minutes. UVB40: UVB light applied to cherries before packaging as bilaterally at a dose of $11.89 \mathrm{~kJ} / \mathrm{m}^{2}$ for 40 minutes. After the applications, cherries were packed and placed in dark conditions in the cold storage.

\section{LED (Light-Emitting Diode) Lighting Device}

Cherries were stored under the device continuously illuminated by three different LEDs, red, blue, and ultraviolet-A (UVA). For LED lighting; A $5 \mathrm{~m}$ LED strip for each light is mounted on a $1 \times 1 \mathrm{~m} \times 80 \mathrm{~cm}$ sized a wooden frame. The surround of the device is covered with black polyethylene to prevent light leakage from any external light source (Kasim ve Kasim, 2017a). Cherries stored in completely dark conditions evaluated as controls

\section{LED Treatments}

After the cherry fruits packaged, they placed under the red (KR), blue (M) and ultraviolet-A (UVA) LED lighting device prepared in the cold storage and continuously illuminated during storage. The wavelengths and properties of the LED lights were determined using the Asensetek Lighting Passport Essence device. PPFD (photosynthetic photon flow intensity) value of the red LED (600-700 nm) light source used is $2.0256 \mu \mathrm{mol} / \mathrm{m}^{2} \mathrm{~s}$; YPFD (photosynthetic photon flow density yield) value is 1,9631 $\mu \mathrm{mol} / \mathrm{m}^{2}$ s. PPFD value of blue LED (400-499 nm) light source is $6,8933 \mu \mathrm{mol} / \mathrm{m}^{2} \mathrm{~s}$; YPFD value is $5,0702 \mu \mathrm{mol} /$ $\mathrm{m}^{2} \mathrm{~s}$. PPFD value of UVA LED (380-399 nm) light source $0,0018 \mu \mathrm{mol} / \mathrm{m}^{2} \mathrm{~s}$; YPFD value was measured as 0.0011 $\mu \mathrm{mol} / \mathrm{m}^{2} \mathrm{~s}$ (Figure 1).

\section{Packaging and Storage Conditions}

The cherries, after the UVB application or before being placed in the LED lighting device and the control group was placed directly in $110 \times 110 \times 50 \mathrm{~mm}$ PVC boxes and the lids were closed. The packed cherry fruits were placed in a cold storage room with a temperature of $4 \pm 1^{\circ} \mathrm{C}$ and $85-90 \%$ relative humidity for 35 days.

\section{Total Soluble Phenol (TSP) Content}

The TSP amount of cherry fruits was determined according to a modified method of Gonzalez-Aguilar et al. (2005). Accordingly, $2400 \mu \mathrm{L}$ distilled water and $150 \mu \mathrm{L}$ folin-ciocaltaeu $(1: 10)$ solution added to the $150 \mu \mathrm{L}$ juice sample and then waited for 2-4 minutes after shaking for 3040 seconds. Then, $300 \mu \mathrm{L}$ of sodium carbonate $\left(\mathrm{Na}_{2} \mathrm{CO}_{3}, 1\right.$ $\mathrm{N})$ added to the solution, and standing for 2 hours at room temperature $\left(20^{\circ} \mathrm{C}\right)$ in dark conditions. The sample reading has done at a wavelength of $725 \mathrm{~nm}$ in a spectrophotometer (Shimadzu, 1240). The TSP amount was calculated via drawing the standard curve by using caffeic acid equivalent (CAE) $\mathrm{mg} / 100 \mathrm{~mL}$.

\section{Total Anthocyanin Content}

The total anthocyanin content of cherry fruits determined according to the $\mathrm{pH}$-differential method (Giusti and Wrolstad, 2001). For this purpose, one gram of fruit sample homogenized by adding $10 \mathrm{~mL}$ of the first buffer ( $\mathrm{pH}: 1)$ solution $(125 \mathrm{~mL} 0.2 \mathrm{M} \mathrm{KCl}+375 \mathrm{~mL} 0.2 \mathrm{M} \mathrm{HCl})$. The homogenized samples have centrifuged at $4^{\circ} \mathrm{C}(15$ minutes at $5000 \mathrm{rpm}$ ), and the reading has been taken in the spectrophotometer at a wavelength of $510 \mathrm{~nm}$. In the second step of the method, $10 \mathrm{~mL}$ of the second buffer $(\mathrm{pH}: 4,5)$ solution $(400 \mathrm{~mL}$ of $1 \mathrm{M}$ sodium acetate $+240 \mathrm{~mL}$ of $1 \mathrm{M}$ $\mathrm{HCl}+360 \mathrm{~mL}$ of water) added to the sample, then homogenized, and centrifuged at $4^{\circ} \mathrm{C}(5000 \mathrm{rpm} ; 15 \mathrm{~min})$ and the supernatant was collected. The final solution had read on the spectrophotometer at a wavelength of $510 \mathrm{~nm}$. The total amount of anthocyanins had calculated as $(\mathrm{mg} / \mathrm{kg}$ fresh weight $(\mathrm{FW})$ ). 


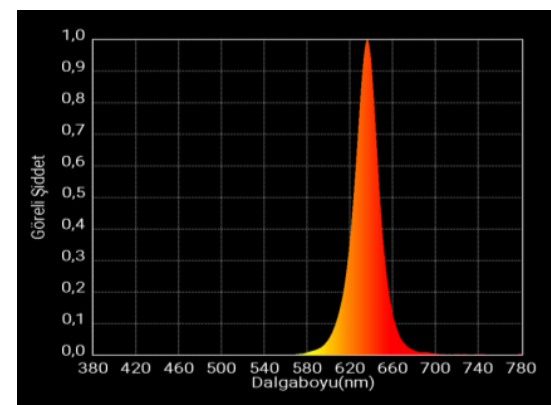

a

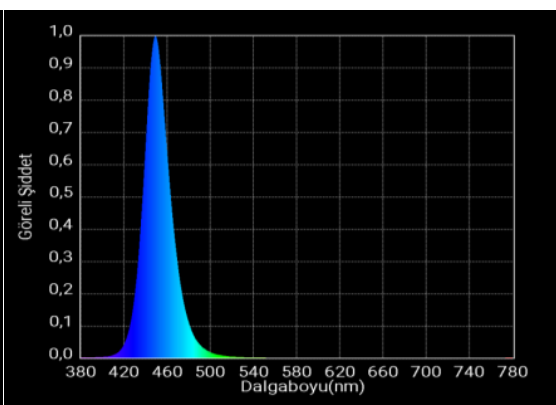

b

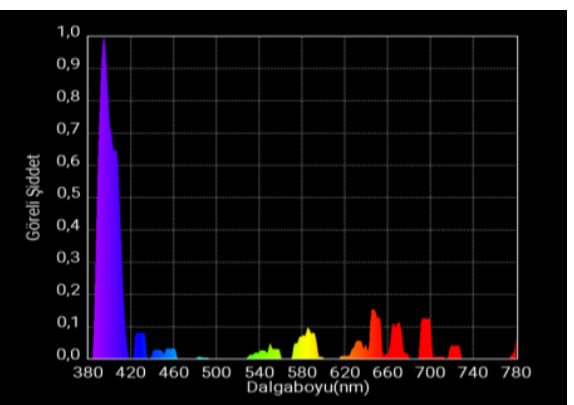

c

Figure 1. The wavelengths and relative intensities of the red (a), blue (b) and UVA LED (c) lights used in the study

\section{Fruit Elasticity}

The elasticity of the fruit $(\mathrm{N})$ was measured by applying $0.5 \mathrm{~cm}$ pressure on the fruit with the texture analyser (Shimadzu EZ-LX) in 5 fruits taken from each repetition.

\section{Fructose, Glucose and Sucrose Content}

$1 \mathrm{~mL}$ of fruit juice was diluted by adding $4 \mathrm{~mL}$ of distilled water. The prepared solution was passed through the injector filter (Nylon $66.25 \mu \mathrm{m}$ ) and injected into highpressure liquid chromatography (HPLC, Agilent, HP 1260, Hewlett Packard, CA / USA) (Kasım and Kasım, 2015). Zorbax Carbohydrate column (4.6 mm ID $\times 150 \mathrm{~mm}(5$ $\mu \mathrm{L})$ ) has used in the study, and the mobile phase set at $75 / 25$ acetonitrile /water and flow rate: $1.4 \mathrm{~mL} / \mathrm{min}$. The column temperature is $30^{\circ} \mathrm{C}$, and the HP1100 RID detector has used. The sample volume used in the study; it is $20 \mu \mathrm{L}$ in 75/25 acetonitrile /water mixture. The amount of sugar in the samples has calculated using the standard curve. The dilution factor has also added to the calculation.

\section{Total Soluble Solids (TSS) Content}

The amount of TSS in fruit juice obtained from cherry fruits measured with the Atago DR-A1 digital refractometer (Atago Co. Ltd. Japan) and expressed in \% (Kasım and Kasım, 2017b).

\section{Titratable Acid Content}

$10 \mathrm{~mL}$ of juice sample had placed in a $100 \mathrm{~mL}$ beaker, and $20 \mathrm{~mL}$ of distilled water added. The solution titrated against $0.1 \mathrm{~N} \mathrm{NaOH}$ at $\mathrm{pH}$ meter. Titration acidity calculated in terms of malic acid according to the amount of $\mathrm{NaOH}$ used (Karaçalı, 2006).

\section{Colour measurement}

Colour measurements have performed from three different points of five fruit samples in each repetition by using a colorimeter (Minolta CR 400 Chroma; Minolta Co., Osaka, Japan) with D65 illumination. $L^{*}, a^{*}, b^{*}$ color space coordinates (CIELAB) had used to express the fruit color. The color meter had calibrated at the beginning of the measurement with the white standard calibration plate of the device $\left(L^{*}=97.52, a^{*}=-5.06, b^{*}=3.57\right)$ (McGuire, 1992; Lancester et al., 1997). In addition, by using the obtained data; hue angle $\left(h^{\circ}\right)$ was calculated as formulas followed; $h^{\circ}$ $=\tan ^{-1}(\mathrm{~b} / \mathrm{a})$ (Kasim and Kasim, 2016b).

\section{Green Stalk Rate (\%)}

In 10 fruits in each repeat, the green ones of the fruit stalk were counted and proportioned to the total number of fruits and expressed as (\%).

\section{Electrolyte Leakage}

Three fruits from each replication cut into two-slice and placed in PET cups $(180 \mathrm{~mL})$. After the prepared samples were washed twice with $50 \mathrm{~mL}$ of distilled water, another $50 \mathrm{~mL}$ of water was added to the cups and incubated for two hours. The electrical conductivity (EC) of the solution measured at the end of the incubation, and then the samples have frozen at $-18^{\circ} \mathrm{C}$ in the deep freezer. The samples taken out of the freezer left to dissolve, and EC measurements made again when the solution temperature reached about $18^{\circ} \mathrm{C}$. The amount of electrolyte leakage from cherry fruits was determined by the proportion of the initial EC and the final EC values and which was expressed in percentage (Kasım and Kasim, 2016a).

\section{Weight Loss (\%)}

Weight loss measurements have made at the beginning of the study, and during each analysis period, and weight losses had expressed in proportion to the initial value (\%).

\section{Visual Quality and Taste Analysis}

Fruits scored in terms of taste and visual quality by using a scale of 1-5 by panellists created for this purpose. The numbers on the scale used in scoring represent 1: very bad, 2: bad, 3: medium, 4: good, and 5: very good.

\section{Experimental Design and Statistical Analysis}

Research had established a completely randomized parcel factorial design with three replications, and three boxes (250 $\mathrm{g}$ fruit/box) used in each replicate. The data subjected to variance analysis using the SPSS 16 package program. Differences between means (treatments, storage duration and treatments $\times$ storage duration) had analysed using Duncan multiple comparison tests $(\mathrm{P}<0.05)$.

\section{Results and Discussion}

Total Soluble Phenol Content (TSP, Mg/100ml CAE)

TSP content, which was $161.14 \mathrm{mg} / 100 \mathrm{~mL}$ CAE at the beginning of the study, was found to be significantly higher $(\mathrm{P}<0.05)$ in KR $(177.42 \mathrm{mg} / 100 \mathrm{~mL} \mathrm{CAE})$ than the other treatments during storage. This treatment was followed by UVB40 (171.02 mg / 100mL CAE), UVB20 (170.16 mg/100mL CAE) and K (170.13 mg/100mL CAE). The amount of TSP had varied between 166.27$169.44 \mathrm{mg} / 100 \mathrm{~mL}$ CAE in fruits treated with LED light (Table 1). The fruit colour, which is initially green in red fruits, turns into the red as a result of phenolic and anthocyanin accumulation, and also due to the chlorophyll breakdown during ripening. Phenolic compounds, which are accumulated in fruit skin increase 
the organoleptic and sensory quality of fruits such as sweetness and astringency. The amount of these compounds in plant increases during the natural development of plants. However, their amount may also increase due to biotic and abiotic stress factors such as infection, injury, or ultraviolet radiation (Koçak and Bal, 2017). In the current study, abiotic stress conditions were created with ultraviolet-B and LED lighting applications in cherries. When the TSP content of the fruits in these conditions evaluated, it showed an increase in all treatments except $\mathrm{M}$ application, but the highest increase was in the KR application. Therefore, it could say that cherry fruits stored under the red LED light condition responding the most to this stress. Similarly, UVB40 and UVB 20 applications also caused an increase in the amount of TSP during storage. The amount of phenolic compounds of cherries fruits varies by variety. Usenik et al. (2008) stated that the amount of TSP varies between 44.3-87.9 mg GAE / $100 \mathrm{~g} \mathrm{FW}$ in cherries. Ferretti et al.
(2010) stated that TSP amount o was $60 \pm 13 \mathrm{mg}$ GAE / $100 \mathrm{~g}$ in Brooks, $75 \pm 14 \mathrm{mg}$ GAE / $100 \mathrm{~g}$ in Newstar, 92 $\pm 12 \mathrm{mg} \mathrm{GAE} / 100 \mathrm{~g}$ in Black Gold, $96 \pm 20 \mathrm{mg} \mathrm{GAE} /$ $100 \mathrm{~g}$ in Hedelfingen, $104 \pm 6 \mathrm{mg} \mathrm{GAE} / 100 \mathrm{~g}$ in Regina, $147 \pm 19 \mathrm{mg}$ GAE / $100 \mathrm{~g}$ in Hartland and $155 \pm 20 \mathrm{mg}$ GAE / $100 \mathrm{~g}$ in Cristalina cherry varieties. So, it was seen that the initial TSP content of 0900 Ziraat cherry fruit higher than the values measured in seven cherry varieties by Ferretti et al. (2010). Torçuk et al. (2016) stated that the amount of phenolic substance of cherry fruits varies during cold storage, and shelf life of fruits, and also the total phenolic substance content of cherry fruits decreases depending on the extending storage time. However, in the study conducted, it found that although the TSP values of 0900 Ziraat vary as increase and decrease during storage, they increased in general compared to the beginning. Therefore, it can be said the applied stress conditions stimulate the accumulation of TSP.

Table 1. The effects of different light treatments on TSP content of 0900 Ziraat cherry fruits during storage (mean \pm SE).

\begin{tabular}{|c|c|c|c|c|c|c|c|}
\hline \multirow{2}{*}{ Treatments } & \multicolumn{6}{|c|}{ Storage duration (days) } & \multirow{2}{*}{$\operatorname{Tr} A^{* *}$} \\
\hline & 0 & 7 & 14 & 21 & 28 & 35 & \\
\hline$\overline{\mathrm{K}}$ & $159.4 \pm 1.48$ & $175.2 \pm 4.84$ & $160.6 \pm 3.74$ & $189.6 \pm 14.53$ & $155.8 \pm 9.55$ & $180.1 \pm 5.05$ & $170.13^{\mathrm{b}}$ \\
\hline KR & $159.4 \pm 1.48$ & $176.6 \pm 12.36$ & $191.9 \pm 32.85$ & $186.6 \pm 11.36$ & $167.1 \pm 1.98$ & $182.9 \pm 10.30$ & $177.42^{\mathrm{a}}$ \\
\hline M & $159.4 \pm 1.48$ & $155.3 \pm 5.92$ & $171.7 \pm 4.58$ & $171.4 \pm 21.34$ & $168.1 \pm 7.39$ & $171.7 \pm 2.16$ & $166.27^{\mathrm{b}}$ \\
\hline UVA & $159.4 \pm 1.48$ & $162.9 \pm 14.68$ & $169.6 \pm 5.43$ & $180.1 \pm 14.00$ & $164.4 \pm 8.10$ & $171.9 \pm 2.42$ & $168.05^{\mathrm{b}}$ \\
\hline UVB10 & $159.4 \pm 1.48$ & $176.4 \pm 14.31$ & $167.1 \pm 0.62$ & $175.4 \pm 7.47$ & $164.8 \pm 5.59$ & $173.5 \pm 2.13$ & $169.44^{\mathrm{b}}$ \\
\hline UVB20 & $159.4 \pm 1.48$ & $171.5 \pm 12.70$ & $160.6 \pm 5.30$ & $193.3 \pm 5.98$ & $168.0 \pm 4.53$ & $168.2 \pm 3.21$ & $170.16^{\mathrm{b}}$ \\
\hline UVB40 & $159.4 \pm 1.48$ & $159.9 \pm 14.03$ & $163.4 \pm 1.27$ & $195.2 \pm 5.24$ & $172.3 \pm 2.64$ & $175.9 \pm 6.18$ & $171.02^{\mathrm{b}}$ \\
\hline SDA* & $159.4^{\mathrm{d}}$ & $168.2^{\mathrm{c}}$ & $169.2^{\mathrm{bc}}$ & $184.5^{\mathrm{a}}$ & $165.7^{\mathrm{c}}$ & $174.9^{\mathrm{b}}$ & \\
\hline
\end{tabular}

K: Control, KR: Red LED, M: Blue LED, UVA: (Ultraviolet-A LED), UVB10 (Ultraviolet-B: 10 min.), UVB20 (Ultraviolet-B: 20 min.), UVB40 (Ultraviolet-B: $40 \mathrm{~min}$.) SDA (Storage duration average), TrA (Treatment average), *The different letters in line represent the significant differences among the storage duration at the level of $\mathrm{P}<0.05$, **The different letters in column represent the significant differences among the treatments at the level of $\mathrm{P}<0.05$ according to the Duncan test.

\section{Total Anthocyanin Content (Mg/Kg FW)}

In the study, the total anthocyanin contents of cherries increased on the seventh day of the storage in the KR (19.99 $\mathrm{mg} / \mathrm{kg} \mathrm{FW}), \mathrm{K}(15.73 \mathrm{mg} / \mathrm{kg} \mathrm{FW})$, and M (15.10 mg/kg FW) whereas it decreased in other treatments. Also, the higher reduction had achieved in the UVB10 treatment (Figure 2). Although the amount of anthocyanins of the fruits generally decreases after this period, it determined that the least reduction occurred in KR, UV20, and UV40 applications. One of the compounds that provide colour formation in cherry is anthocyanins, and the decrease in the amount of these compounds causes colour lightening and hence decrease in $h^{\circ}$. Şen and Kuzucu (2016) stated that the content of anthocyanins in the cherries stored immediately after harvest showed a rapid decrease in all applications, and followed a more stable composition during storage. In the present study, the anthocyanin content of cherries increased on the seventh day of storage in $\mathrm{KR}, \mathrm{K}$, and $\mathrm{M}$ treatments, whereas it decreased in others. After this period, the anthocyanin content of cherries had changed in the form of a decrease and increase. However, it remained below the initial value in all treatments at the end of the storage period. It might be due to the darkening of the fruit colour after the $14^{\text {th }}$ day of the storage. Anthocyanin amounts may be different in different cherry varieties. Consequently, it has determined that the amount of anthocyanins is obtained by $10 \pm 2,20 \pm 5,30 \pm 9,40 \pm 7,41 \pm 2$ and $76 \pm 12 \mathrm{mg}$ GAE/100 g in Brooks, Newstar, Black Gold, Hedelfingen,
Regina, Hartland, and Cristalina, respectively (Usenik et al., 2008). In the study, it could be said that the anthocyanin content of 0900 Ziraat cherry $(13.13-15.03 \mathrm{mg} / \mathrm{kg}$ ) of has higher than Brooks and lower than other varieties.

\section{Fruit Elasticity $(N)$}

The present study showed reduced fruit elasticity after the 7 day of storage (Figure 3). However, it has found that the highest elasticity value has obtained from the KR treatment $(27.06 \mathrm{~N})$ and followed by UVA (26.48) and K $(26.26 \mathrm{~N})$ treatments during the storage period. In cherry fruits, the elasticity of the fruit increases as the fruit softens. As a matter of fact, the current research showed that the fruit elasticity values in the UVB40, UVB20, and M treatment lower than the other treatments during the 28 days of storage. In this respect, the best treatment was UVB40, followed by other UVB20 and M LED light, so it could say that the light treatments caused the fruits to remain harder. In the literature review, no studies on the effects of ultraviolet-B light and LED lighting had found in preserving the quality of the cherries after harvest. In other studies, however, it has been stated that modified atmosphere packaging (MAP) treatment increases fruit firmness in cherry fruits (Wang and Long, 2014). Besides, it has been expressed MAP treatment together with rapid cooling are maintains the fruit elasticity values as low of 0900 Ziraat cherry fruits during eight days of storage at $0^{\circ} \mathrm{C}$ temperature (Özkaya et al., 2015). 


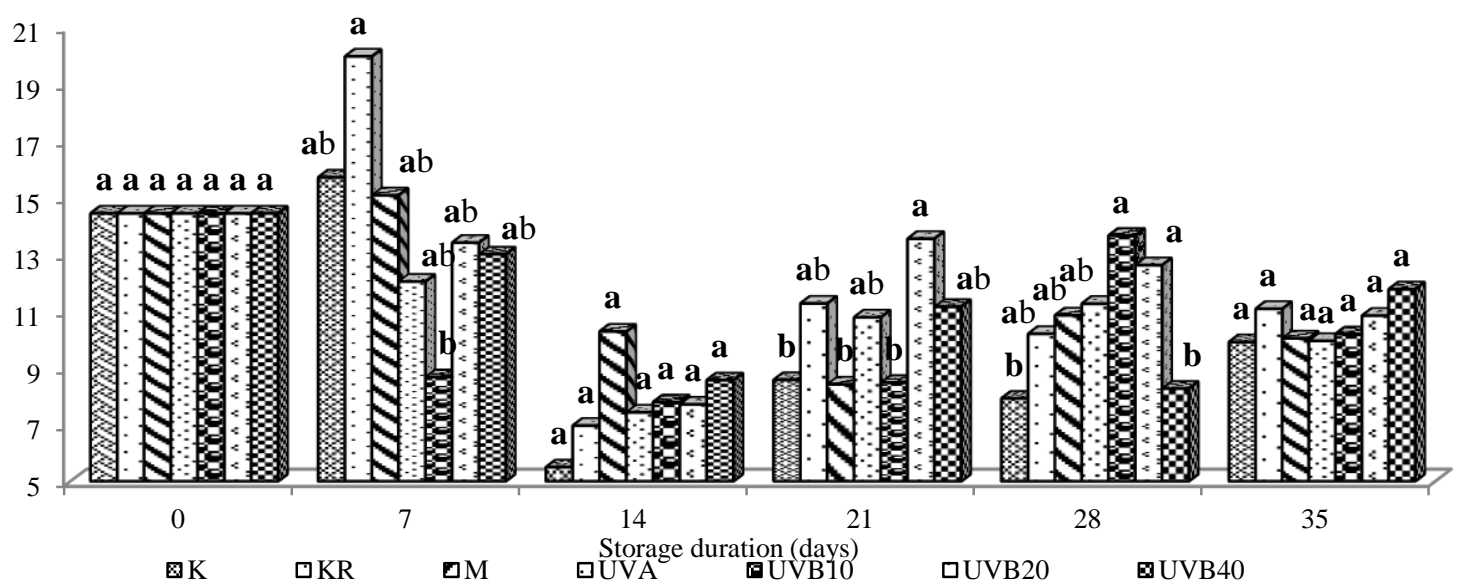

Figure 2. Changes in the anthocyanin content during the storage of fruits of 0900 Ziraat cherry variety. The letters shown on the columns indicate that the differences between applications are statistically significant at the level of $\mathrm{P}<0.05$ according to the Duncan test.

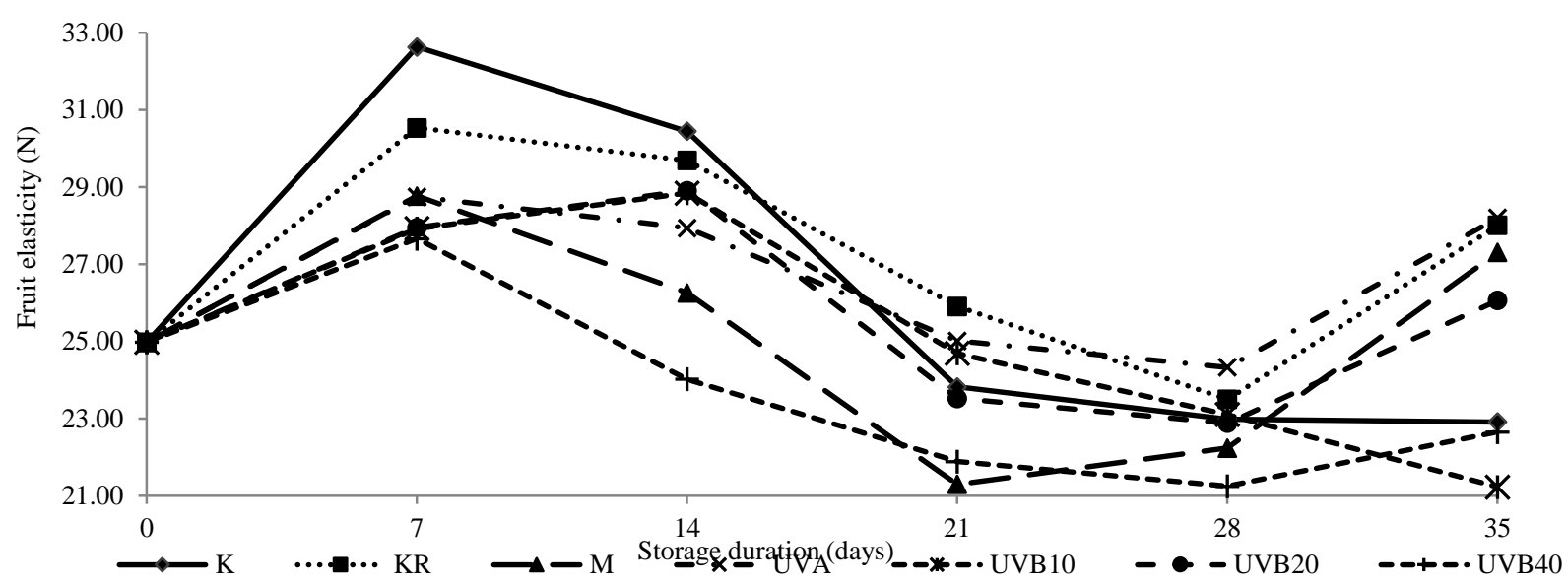

Figure 3. Changes of elasticity values of 0900 Ziraat cherry variety of fruits during the storage.

In this study, since the cherries in all treatment groups stored in a PVC box, it was thought that packaging along with UV-B and LED treatments to have effective in terms of preserving fruit firmness. In conclusion, it could say that UVB40 treatment significantly reduces the elasticity values and also delayed the softening of fruits compared to other applications. So, it concluded that UVB10, M, and UVB20 treatments along with UVB40 come to the fore with this respect.

Total Soluble Solids (TSS, \%), Titratable Acidity (TA, G/100ml), TSS/TA Rate

In the experiment, it was found that the TSS content of cherry fruits was maintained more than other treatments, especially in the UVB20 treatment, also was followed by $\mathrm{K}$ and UVB40 treatments. The lowest TSS content had determined in $\mathrm{M}$ and UVA treatments (Table 2). The titratable acid (TA) content of cherry fruits decreased until the $28^{\text {th }}$ day of storage in all treatments. However, the higher reduction of the TA content occurred in the UVB20 $(0.75 \mathrm{~g} / 100 \mathrm{~mL})$ treatment, whereas the least decreasing was noticed in $\mathrm{K}(0.81 \mathrm{~g} / 100 \mathrm{~mL})$ (Table 2$)$. In the study, it had found that the TSS/TA content is statistically significant higher $(\mathrm{P}<0.05)$ in UVB20 (17.89) compared to other treatments. The UVB20 and UVB40 applications resulted in the protection or increase of the amount of TSS, while the amount of TSS decreased in the cherry fruits held in LEDs of different colors. Particularly $\mathrm{M}$ and UVA treatments have found to accelerate the breakdown of water-soluble sugars. It can be stated that the amount of TSS $(15.36 \%)$ in the 'Regina' cherry variety stored after UV-C application decreased during storage (Şen and Kuzucu 2016). Whereas, in the current study, the amount of TSS increased during the storage, especially in fruits with high ultraviolet doses such as UVB40 and UVB20. Ultraviolet light treatments to fruit and vegetable products after harvest cause stimulation of the defense mechanism in the products as well as surface disinfection which might to increase soluble carbohydrates content to protect itself against stress conditions. Kasim and Kasim (2015) reported an increase the TSS content in Tayfun $\mathrm{F}_{1}$ tomato treated with UV-B. Also, in the present study, abiotic stress conditions created with different LED treatments caused a significant decrease in the TSS content of fruits compared to other treatments. Although fruits contained different types of organic acids, it had stated that the acidity in cherry fruits composed of malic acid (85\%) (Koçak and Bal, 2017). In the previous studies, it was stated that the TA content decreased continuously during storage in Lapins (Meheriuk et al., 1995) and 0900 Ziraat (Koçak and Bal 2017) varieties. In the experiment, the TA content of fruits decreased in all treatments during storage, but the most decrease occurred in cherries in the UVB20 treatment. Again in the previous studies, it was declared 
that the TA content was changed from $0.49-1.39 \%$ in 0900 Ziraat cherry (Yıldırım and Koyuncu, 2010; Çetinbaş et al., 2012; Kurubaş et al., 2017), 0.50-1\% in Brooks and Bing cherry varieties (Crisosto et al., 2003), and also it was $0.66 \%, 0.58 \%, 0.5 \%, 0.48 \%$, and $0.44 \%$ in Bing, Kordia, Van, Sweetheart, and Lapin varieties respectively (San Martino et al., 2008). In the present study, it had found that the titration acidity values 0900 Ziraat cherry fruits varied between $0.59-0.92 \mathrm{~g} / 100 \mathrm{~mL}$ during storage, and it can be said that this result agreed with the previous studies done by Yıldırım and Koyuncu (2010); Çetinbaş et al. (2012); Kurubaş et al. (2017). It can be said all the treatments performed in the study increased the TSS/TA ratio compared to the control group, however it did not support by taste scores (Table 4). In previous studies, it had found that there is a medium level relation between perceived sweetness and TSS/TA ratio and a very high level of correlation between sourness and TSS/TA. In cherries, it can be stated that the balance between sweetness and sourness is significant and if the titration acidity is above $0.6 \%$ and the amount of TSS is less than $1 \%$ the consumer preference decreases and the optimum sweet-sour balance is between 1.5 and 2 (TSS /TA mL NaOH) (Kappel et al., 1996). Therefore, similar to the previous study, the amount of TSS in cherry fruits was preserved close to or higher than the initial value in UVB40 and UVB20 treatments, and the amount of titratable acid in UVB and LED light-treated fruits is also significantly reduced in the present study.

Table 2. TSS, TA, TSS/TA, fructose, glucose and sucrose of 0900 Ziraat cherry fruits during storage (mean $\pm \mathrm{SE}$ ).

\begin{tabular}{|c|c|c|c|c|c|c|c|c|c|}
\hline $\mathrm{C}$ & SD & $\mathrm{K}$ & KR & $\mathrm{M}$ & UVA & UVB10 & UVB20 & UVB40 & SDA* \\
\hline \multirow{7}{*}{ TSS } & 0 & $14.1 \pm 0.55$ & $14.1 \pm 0.55$ & $14.1 \pm 0.55$ & $14.1 \pm 0.55$ & $14.1 \pm 0.55$ & $14.1 \pm 0.55$ & $14.1 \pm 0.55$ & $14.07^{\mathrm{b}}$ \\
\hline & 7 & $14.4 \pm 0.72$ & $15.0 \pm 0.21$ & $14.7 \pm 0.61$ & $14.0 \pm 0.26$ & $13.9 \pm 0.15$ & $15.0 \pm 0.76$ & $15.0 \pm 0.36$ & $14.57^{\mathrm{a}}$ \\
\hline & 14 & $14.3 \pm 0.84$ & $13.5 \pm 1.05$ & $13.4 \pm 0.61$ & $14.2 \pm 1.39$ & $14.4 \pm 0.40$ & $14.6 \pm 0.40$ & $13.3 \pm 0.26$ & $13.97 \mathrm{~b}$ \\
\hline & 21 & $14.7 \pm 0.45$ & $14.0 \pm 0.64$ & $13.5 \pm 0.44$ & $13.1 \pm 0.31$ & $13.5 \pm 0.72$ & $13.8 \pm 0.87$ & $14.2 \pm 0.25$ & $13.83^{b}$ \\
\hline & 28 & $13.9 \pm 0.85$ & $13.2 \pm 1.21$ & $13.2 \pm 0.40$ & $13.8 \pm 0.32$ & $14.1 \pm 0.26$ & $14.5 \pm 0.47$ & $13.5 \pm 0.15$ & $13.74^{b}$ \\
\hline & 35 & $13.5 \pm 0.84$ & $14.1 \pm 0.35$ & $13.6 \pm 0.36$ & $13.8 \pm 0.47$ & $13.9 \pm 0.60$ & $14.0 \pm 1.12$ & $14.2 \pm 0.15$ & $13.87^{b}$ \\
\hline & $\operatorname{Tr} A^{* *}$ & $14.15^{\mathrm{ab}}$ & $13.97^{\mathrm{ab}}$ & $13.75^{\mathrm{b}}$ & $13.83^{\mathrm{b}}$ & $13.98^{\mathrm{ab}}$ & $14.32^{\mathrm{a}}$ & $14.05^{\mathrm{ab}}$ & \\
\hline \multirow{7}{*}{ TA } & 0 & $0.92 \pm 0.055$ & $.92 \pm 0.055$ & $92 \pm 0.055$ & $.92 \pm 0.055$ & $0.92 \pm 0.055$ & $0.92 \pm 0.055$ & $0.92 \pm 0.055$ & $0.92^{\mathrm{a}}$ \\
\hline & 7 & $0.90 \pm 0.028$ & $0.86 \pm 0.030$ & $0.89 \pm 0.055$ & $0.85 \pm 0.030$ & $0.91 \pm 0.005$ & $0.83 \pm 0.020$ & $0.86 \pm 0.022$ & $0.87^{\mathrm{b}}$ \\
\hline & 14 & $0.81 \pm 0.010$ & $0.77 \pm 0.012$ & $0.77 \pm 0.012$ & $0.77 \pm 0.035$ & $0.80 \pm 0.009$ & $0.74 \pm 0.012$ & $0.78 \pm 0.013$ & $0.77^{\mathrm{d}}$ \\
\hline & 21 & $0.73 \pm 0.028$ & $0.69 \pm 0.030$ & $0.65 \pm 0.031$ & $0.69 \pm 0.045$ & $0.69 \pm 0.021$ & $0.65 \pm 0.006$ & $0.69 \pm 0.019$ & $0.68^{\mathrm{e}}$ \\
\hline & 28 & $0.71 \pm 0.010$ & $0.62 \pm 0.020$ & $0.59 \pm 0.031$ & $0.66 \pm 0.028$ & $0.62 \pm 0.020$ & $0.59 \pm 0.028$ & $0.65 \pm 0.025$ & $0.63^{f}$ \\
\hline & 35 & $0.78 \pm 0.022$ & $0.82 \pm 0.032$ & $0.77 \pm 0.039$ & $0.83 \pm 0.012$ & $0.88 \pm 0.080$ & $0.78 \pm 0.004$ & $0.85 \pm 0.064$ & $0.81^{\mathrm{c}}$ \\
\hline & $\operatorname{Tr} A * *$ & $0.81^{\mathrm{a}}$ & $0.78^{\mathrm{bc}}$ & $0.76^{\mathrm{cd}}$ & $0.78^{\mathrm{abc}}$ & $0.80^{\mathrm{ab}}$ & $0.75^{\mathrm{d}}$ & $0.79^{\mathrm{ab}}$ & \\
\hline \multirow{7}{*}{ TSS/TA } & 0 & $15.3 \pm 0.47$ & $15.3 \pm 0.47$ & $15.3 \pm 0.47$ & $15.3 \pm 0.47$ & $15.3 \pm 0.47$ & $15.3 \pm 0.47$ & $15.3 \pm 0.47$ & $15.3^{\mathrm{e}}$ \\
\hline & 7 & $16.1 \pm 1.33$ & $17.5 \pm 0.83$ & $16.7 \pm 1.77$ & $16.6 \pm 0.35$ & $15.2 \pm 0.09$ & $18.0 \pm 0.48$ & $17.4 \pm 0.40$ & $16.7^{\mathrm{d}}$ \\
\hline & 14 & $17.7 \pm 0.83$ & $17.5 \pm 1.10$ & $17.5 \pm 1.01$ & $18.5 \pm 1.97$ & 0.71 & $19.7 \pm 0.34$ & $17.2 \pm 0.56$ & $17.9^{c}$ \\
\hline & 21 & $20.2 \pm 0.74$ & $20.3 \pm 1.66$ & $20.8 \pm 0.34$ & $19.1 \pm 1.47$ & $19.7 \pm 1.66$ & $21.1 \pm 1.43$ & $20.6 \pm 0.68$ & $20.2^{\mathrm{b}}$ \\
\hline & 28 & $19.5 \pm 1.05$ & $21.4 \pm 2.67$ & $22.4 \pm 0.88$ & $21.0 \pm 0.61$ & $22.6 \pm 1.06$ & $24.5 \pm 0.49$ & $21.0 \pm 0.57$ & $21.7^{\mathrm{a}}$ \\
\hline & 35 & $17.3 \pm 1.43$ & $17.2 \pm 1.03$ & $17.7 \pm 0.78$ & $16.7 \pm 0.41$ & $15.9 \pm 0.81$ & $17.9 \pm 1.42$ & $16.7 \pm 1.35$ & $17.0^{\mathrm{d}}$ \\
\hline & $\operatorname{Tr} A^{*}$ & $17.6^{\mathrm{b}}$ & $18.2^{\mathrm{b}}$ & $18.3^{\mathrm{b}}$ & $17.8^{\mathrm{b}}$ & $17.7^{b}$ & $19.3^{\mathrm{a}}$ & $18.0^{\mathrm{b}}$ & \\
\hline \multirow{7}{*}{ Fructose } & 0 & $5.15 \pm 0.03$ & $5.15 \pm 0.03$ & $5.15 \pm 0.03$ & $5.15 \pm 0.03$ & $5.15 \pm 0.03$ & $5.15 \pm 0.03$ & $5.15 \pm 0.03$ & $5.17^{\mathrm{a}}$ \\
\hline & 7 & $4.23 \pm 1.09$ & $5.16 \pm 0.37$ & $4.76 \pm 0.16$ & $4.99 \pm 0.12$ & 4.84 & $5.20=$ & $5.07 \pm 0.11$ & $4.89^{\mathrm{b}}$ \\
\hline & 14 & $5.03 \pm 0.65$ & $4.62 \pm 0.36$ & $4.84 \pm 0.27$ & $4.54 \pm 0.09$ & $4.95=$ & $5.31=$ & $4.67 \pm 0.21$ & $4.85^{\mathrm{b}}$ \\
\hline & 21 & $4.69 \pm 1.15$ & $4.79 \pm 0.30$ & $4.64 \pm 0.42$ & $4.62 \pm 0.12$ & $4.21 \pm 0.68$ & $4.57 \pm 0.27$ & $4.82 \pm 0.19$ & $4.62^{c}$ \\
\hline & 28 & $5.23 \pm 0.33$ & $5.32 \pm 0.57$ & $5.12 \pm 0.37$ & $5.51 \pm 0.14$ & $5.45 \pm 0.09$ & $5.82 \pm 0.07$ & $5.14 \pm 0.10$ & $5.37^{\mathrm{a}}$ \\
\hline & 35 & $4.89 \pm 0.73$ & $5.64 \pm 0.21$ & $5.09 \pm 0.14$ & $5.42 \pm 0.26$ & 0.11 & $5.56 \pm 0.13$ & $5.52 \pm 0.14$ & $5.30^{\mathrm{a}}$ \\
\hline & $\operatorname{Tr} A^{*}$ & $4.87^{\mathrm{b}}$ & $5.11^{\mathrm{ab}}$ & $4.93^{\mathrm{b}}$ & $5.04^{\mathrm{ab}}$ & $4.93^{\mathrm{b}}$ & $5.27^{\mathrm{a}}$ & $5.10^{\mathrm{ab}}$ & \\
\hline \multirow{7}{*}{ Glucose } & 0 & $6.25 \pm 0.05$ & $6.25 \pm 0.05$ & $6.25 \pm 0.05$ & $6.25 \pm 0.05$ & $6.25 \pm 0.05$ & $6.25 \pm 0.05$ & $6.25 \pm 0.05$ & $6.24^{\mathrm{a}}$ \\
\hline & 7 & $5.17 \pm 1.27$ & $6.24 \pm 0.43$ & $6.27 \pm 0.41$ & $6.13 \pm 0.13$ & $5.89 \pm 0.10$ & $6.35 \pm 0.07$ & $6.21 \pm 0.12$ & $5.79^{\mathrm{bc}}$ \\
\hline & 14 & $6.13 \pm 0.84$ & $5.96 \pm 0.25$ & $5.88 \pm 0.28$ & $5.63 \pm 0.12$ & $6.03 \pm 0.13$ & $6.47 \pm 0.23$ & $5.68 \pm 0.24$ & $5.96^{\mathrm{ab}}$ \\
\hline & 21 & $5.66 \pm 1.38$ & $5.73 \pm 0.34$ & $5.58 \pm 0.48$ & $5.61 \pm 0.09$ & $5.15 \pm 0.82$ & $5.48 \pm 0.37$ & $5.61 \pm 0.25$ & $5.54^{\mathrm{c}}$ \\
\hline & 28 & $6.03 \pm 0.41$ & $6.02 \pm 0.57$ & $5.69 \pm 0.43$ & $6.23 \pm 0.12$ & $6.24 \pm 0.09$ & $6.62 \pm 0.11$ & $5.86 \pm 0.12$ & $6.09^{\mathrm{ab}}$ \\
\hline & 35 & $5.45 \pm 0.76$ & $6.30 \pm 0.15$ & $5.73 \pm 0.31$ & $6.01 \pm 0.22$ & $5.78 \pm 0.05$ & $6.12 \pm 0.20$ & $6.10 \pm 0.17$ & $5.92^{\mathrm{abc}}$ \\
\hline & $\operatorname{Tr} A^{*}$ & $5.78^{\mathrm{ab}}$ & $6.08^{\mathrm{ab}}$ & $5.90^{\mathrm{ab}}$ & $5.98^{\mathrm{ab}}$ & $5.89^{\mathrm{ab}}$ & $6.22^{\mathrm{a}}$ & $5.68^{\mathrm{b}}$ & \\
\hline \multirow{7}{*}{ Sucrose } & 0 & $0.45 \pm 0.01$ & $0.45 \pm 0.01$ & $0.45 \pm 0.01$ & $0.45 \pm 0.01$ & $0.45 \pm 0.01$ & $0.45 \pm 0.01$ & $0.45 \pm 0.01$ & $0.45^{\mathrm{a}}$ \\
\hline & 7 & $0.43 \pm 0.01$ & - & - & - & - & - & $0.39 \pm 0.01$ & $0.11^{\mathrm{b}}$ \\
\hline & 14 & - & - & - & - & - & - & - & $0.00^{\mathrm{c}}$ \\
\hline & 21 & - & - & - & - & - & - & - & $0.00^{c}$ \\
\hline & 28 & - & - & - & - & - & - & - & $0.00^{\mathrm{c}}$ \\
\hline & 35 & - & - & - & - & - & - & - & $0.00^{c}$ \\
\hline & $\operatorname{TrA} * *$ & $0.15^{\mathrm{a}}$ & $0.07^{\mathrm{c}}$ & $0.07^{\mathrm{c}}$ & $0.07^{\mathrm{c}}$ & $0.07^{\mathrm{c}}$ & $0.07^{\mathrm{c}}$ & $0.14^{\mathrm{b}}$ & \\
\hline
\end{tabular}

C: Criteria, SD: Storage duration (days), K: Control, KR: Red LED, M: Blue LED, UVA: (Ultraviolet-A LED), UVB10 (Ultraviolet-B: 10 min.), UVB20 (Ultraviolet-B: $20 \mathrm{~min}$.), UVB40 (Ultraviolet-B: $40 \mathrm{~min}$.) SDA (Storage duration average), $\operatorname{Tr} A$ (Treatment average), *The different letters in line represent the significant differences among the storage duration at the level of $\mathrm{P}<0.05$, **The different letters in column represent the significant differences among the treatments at the level of $\mathrm{P}<0.05$ according to the Duncan test. 


\section{Fructose, Glucose and Sucrose Content (\%)}

In the research, it has observed that the fructose content of cherry fruits in UVB treatments during storage was higher than other treatments in general. According to the Table 2, in the present study, the highest fructose content average was found in UVB20 (5.27\%) and was followed by the KR, UVB40, UVA, M, UVB10, and K $(5.11 \% ; 5.10 \% ; 5.04 \%$, $4.93 \%, 4.93$, and 4.87 , respectively). Although the glucose content of the fruits changed similarly to the amount of fructose, it has found that the overall glucose content is higher than fructose (Table 2), and varied between 3.72 and $6.64 \%$ during storage. Although the sucrose $(0.46 \mathrm{mg} / \mathrm{kg})$ has measured in all treatments at the beginning of the experiment, it decreased to $0.44 \mathrm{mg} / \mathrm{kg}$ in $\mathrm{K}$ and $0.40 \mathrm{mg} / \mathrm{kg}$ in UVB40, but there was no sucrose has found in the other treatments. The sweetness of the fruit is one of the significant factors that determine the fruit quality, and the flavor of the mesocarp is directly proportional to the composition of the sugar contained in the fruit (Genard et al., 2003). Sucrose from sugars found in fruits consists of fructose and glucose monosaccharides. Therefore, despite the accumulation of sucrose while the fruit is on the tree, it breaks down during storage and turns into fructose and glucose. Also, fructose dissolves more than other sugars and crystallizes more difficult (Anonymous, 2009). In the study, it had found that the UVB20 treatment provides protection of fructose and glucose content, but UVB40 decreases glucose content. On the other hand, sucrose had determined to break completely after fourteenth days in all treatment groups. In the study, the TSS/TA ratio of cherries in UVB20 treatment had found to be high, and it also determined that UVB40 and UV20 treatments increased the TSS content. Therefore, these results were directly proportional to the increase in the amount of fructose and glucose. It had reported that fructose, glucose, and sucrose contents of fully ripe cherry fruits in different ripening periods are $2.35 \pm 0.17$ (g / 100g TA), $0.39 \pm 0.01(\mathrm{~g} / 100 \mathrm{~g}$ TA) and $0.13 \pm 0.01$ TA, respectively (Mahmood et al., 2012). Again in a study, it found that the fructose content $(7.73 \%)$ of Stella variety was higher than Regina, Karina, and Creska, whereas the glucose content of Regina (7.62\%) was higher than others. Besides, it has determined that the sucrose content in all cultivars was low, but the least sucrose content was in Regina with $0.003 \%$, whereas the highest was in Creska with $0.183 \%$ (Vocá et al., 2008). In the present study, the fructose, glucose, and sucrose content of cherries at the beginning of the experiment are quite higher than obtained by Mahmood et al. (2012) and was close to the results of Vocá et al. (2008). This difference might be due to the varieties used in this study were different. Also, in the literature search, no studies found on the changes in the amount of fructose, glucose, and sucrose during the storage of cherry fruits.

Table 3. Colour values of 0900 Ziraat cherry variety fruits during the storage (mean $\pm \mathrm{SE}$ ).

\begin{tabular}{|c|c|c|c|c|c|c|c|c|c|}
\hline $\bar{C}$ & SD & $\bar{K}$ & KR & $\bar{M}$ & $\overline{\mathrm{UVA}}$ & UVB10 & UVB20 & UVB40 & SDA* \\
\hline \multirow{7}{*}{$L^{*}$} & 0 & $26.2 \pm 0.21$ & $26.2 \pm 0.21$ & $26.2 \pm 0.21$ & $26.2 \pm 0.21$ & $26.2 \pm 0.21$ & $26.2 \pm 0.21$ & $26.2 \pm 0.21$ & $26.2^{\mathrm{d}}$ \\
\hline & 7 & $29.2 \pm 0.67$ & $27.5 \pm 0.44$ & $28.9 \pm 0.24$ & $29.0 \pm 1.12$ & $30.0 \pm 0.36$ & $28.6 \pm 1.55$ & $29.0 \pm 1.79$ & $28.8^{a}$ \\
\hline & 14 & $27.8 \pm 1.73$ & $30.3 \pm 1.39$ & $27.5 \pm 1.21$ & $29.2 \pm 1.69$ & $28.1 \pm 0.86$ & $27.4 \pm 0.76$ & $28.2 \pm 0.45$ & $28.3^{\mathrm{ab}}$ \\
\hline & 21 & $28.1 \pm 0.79$ & $26.6 \pm 0.51$ & $27.5 \pm 1.86$ & $28.9 \pm 1.38$ & $28.9 \pm 1.38$ & $26.5 \pm 0.63$ & $27.8 \pm 1.89$ & $27.7^{\mathrm{bc}}$ \\
\hline & 28 & $27.6 \pm 1.70$ & $27.6 \pm 1.81$ & $27.3 \pm 1.90$ & $28.4 \pm 1.01$ & $27.3 \pm 0.69$ & $26.6 \pm 0.86$ & $27.4 \pm 0.21$ & $27.4^{\mathrm{c}}$ \\
\hline & 35 & $27.7 \pm 0.85$ & $27.7 \pm 0.86$ & $27.3 \pm 1.02$ & $27.6 \pm 1.13$ & $17.6 \pm 1.65$ & $26.4 \pm 0.78$ & $26.8 \pm 0.79$ & $27.2^{\mathrm{c}}$ \\
\hline & $\operatorname{TrA} * *$ & $27.7^{\mathrm{a}}$ & $27.6^{\mathrm{ab}}$ & $27.4^{\mathrm{ab}}$ & $28.2^{\mathrm{a}}$ & $28.0^{\mathrm{a}}$ & $26.9^{\mathrm{b}}$ & $27.5^{\mathrm{ab}}$ & \\
\hline \multirow{7}{*}{$a^{*}$} & 0 & $28.5 \pm 0.09$ & $28.5 \pm 0.09$ & $28.5 \pm 0.09$ & $28.5 \pm 0.09$ & $28.5 \pm 0.09$ & $28.5 \pm 0.09$ & $28.5 \pm 0.09$ & $28.5 a$ \\
\hline & 7 & $29.9 \pm 2.24$ & $27.0 \pm 1.69$ & $29.3 \pm 0.47$ & $29.5 \pm 1.05$ & $30.3 \pm 1.15$ & $27.8 \pm 1.59$ & $27.3 \pm 0.47$ & $28.7 \mathrm{a}$ \\
\hline & 14 & $29.3 \pm 1.95$ & $31.7 \pm 2.67$ & $26.8 \pm 0.66$ & $29.9 \pm 1.19$ & $28.8 \pm 1.74$ & $26.0 \pm 0.43$ & $26.8 \pm 0.53$ & $28.4 \mathrm{a}$ \\
\hline & 21 & $22.2 \pm 0.82$ & $19.6 \pm 0.91$ & $22.1 \pm 3.24$ & $24.6 \pm 3.25$ & $23.6 \pm 1.77$ & $18.9 \pm 1.93$ & $23.0 \pm 3.23$ & $22.0 \mathrm{~b}$ \\
\hline & 28 & $19.8 \pm 2.21$ & $19.4 \pm 4.90$ & $19.3 \pm 2.33$ & $21.8 \pm 1.45$ & $20.0 \pm 2.61$ & $18.0 \pm 1.63$ & $19.9 \pm 2.27$ & $19.7 \mathrm{c}$ \\
\hline & 35 & $20.3 \pm 3.00$ & $20.6 \pm 1.17$ & $20.0 \pm 2.07$ & $21.8 \pm 2.60$ & $20.1 \pm 4.03$ & $15.9 \pm 2.88$ & $19.1 \pm 1.67$ & $19.6 \mathrm{c}$ \\
\hline & $\operatorname{TrA} * *$ & $24.9^{\mathrm{ab}}$ & $24.4^{\mathrm{b}}$ & $24.3^{b}$ & $26.0^{\mathrm{a}}$ & $25.2^{\mathrm{ab}}$ & $22.5 c$ & $24.1^{\mathrm{b}}$ & \\
\hline \multirow{7}{*}{$b^{*}$} & 0 & $9.1 \pm 0.52$ & $9.1 \pm 0.52$ & $9.1 \pm 0.52$ & $9.1 \pm 0.52$ & $9.1 \pm 0.52$ & $9.1 \pm 0.52$ & $9.1 \pm 0.52$ & $9.1^{\mathrm{b}}$ \\
\hline & 7 & $11.0 \pm 1.10$ & $8.6 \pm 1.23$ & $10.5 \pm 0.39$ & $10.4 \pm 1.19$ & $11.3 \pm 1.18$ & $9.7 \pm 2.01$ & $10.0 \pm 1.00$ & $10.2^{\mathrm{a}}$ \\
\hline & 14 & $10.4 \pm 1.76$ & $12.3 \pm 2.27$ & $8.3 \pm 0.63$ & $10.9 \pm 0.80$ & $10.0 \pm 1.01$ & $8.7 \pm 0.89$ & $8.4 \pm 0.39$ & $9.8^{\mathrm{a}}$ \\
\hline & 21 & $6.7 \pm 0.34$ & $5.2 \pm 0.44$ & $6.0 \pm 1.75$ & $8.0 \pm 2.00$ & $7.7 \pm 1.45$ & $5.1 \pm 0.68$ & $7.0 \pm 1.85$ & $6.5^{\mathrm{c}}$ \\
\hline & 28 & $5.8 \pm 1.51$ & $5.3 \pm 2.07$ & $5.0 \pm 1.17$ & $6.1 \pm 0.63$ & $5.4 \pm 1.24$ & $4.3 \pm 0.40$ & $5.4 \pm 0.87$ & $5.3^{\mathrm{d}}$ \\
\hline & 35 & $5.5 \pm 1.45$ & $5.4 \pm 0.85$ & $5.2 \pm 0.96$ & $5.7 \pm 1.22$ & $5.6 \pm 2.32$ & $3.6 \pm 1.04$ & $5.0 \pm 0.85$ & $5.1^{\mathrm{d}}$ \\
\hline & $\operatorname{TrA} * *$ & $8.0^{\mathrm{ab}}$ & $7.6^{\mathrm{ab}}$ & $7.3^{\mathrm{bc}}$ & $8.3^{\mathrm{a}}$ & $8.1^{\mathrm{ab}}$ & $6.7^{\mathrm{c}}$ & $7.4^{\mathrm{bc}}$ & \\
\hline \multirow{7}{*}{ Hue } & 0 & $17.7 \pm 0.90$ & $17.7 \pm 0.90$ & $17.7 \pm 0.90$ & $17.7 \pm 0.90$ & $17.7 \pm 0.90$ & $17.7 \pm 0.90$ & $17.7 \pm 0.90$ & $17.7^{\mathrm{b}}$ \\
\hline & 7 & $20.3 \pm 0.51$ & $17.6 \pm 1.33$ & $19.7 \pm 0.70$ & $19.3 \pm 1.49$ & $20.4 \pm 1.28$ & $19.1 \pm 2.80$ & $20.1 \pm 1.79$ & $19.4^{\mathrm{a}}$ \\
\hline & 14 & $19.5 \pm 2.07$ & $21.1 \pm 1.95$ & $17.3 \pm 0.96$ & $20.1 \pm 0.65$ & $19.1 \pm 0.74$ & $18.5 \pm 1.52$ & $17.5 \pm 0.50$ & $18.9^{\mathrm{a}}$ \\
\hline & 21 & $16.7 \pm 1.22$ & $14.9 \pm 0.64$ & $15.0 \pm 2.11$ & $17.9 \pm 2.38$ & $18.0 \pm 1.99$ & $15.1 \pm 0.65$ & $16.6 \pm 2.25$ & $16.3^{c}$ \\
\hline & 28 & $16.1 \pm 2.62$ & $14.9 \pm 2.20$ & $14.4 \pm 1.64$ & $15.5 \pm 0.58$ & $15.0 \pm 1.70$ & $13.6 \pm 0.62$ & $15.1 \pm 0.72$ & $14.9^{\mathrm{d}}$ \\
\hline & 35 & $15.0 \pm 1.81$ & $14.6 \pm 1.41$ & $14.4 \pm 1.33$ & $14.7 \pm 1.38$ & $15.0 \pm 2.92$ & $12.6 \pm 1.68$ & $14.6 \pm 1.19$ & $14.4^{\mathrm{d}}$ \\
\hline & $\operatorname{TrA} * *$ & $17.55^{\mathrm{a}}$ & $16.80^{\mathrm{ab}}$ & $16.41^{\mathrm{ab}}$ & $17.53^{\mathrm{a}}$ & $17.54^{\mathrm{a}}$ & $16.11^{\mathrm{b}}$ & $16.92^{\mathrm{ab}}$ & \\
\hline
\end{tabular}

C: Criteria, SD: Storage duration (days), K: Control, KR: Red LED, M: Blue LED, UVA: (Ultraviolet-A LED), UVB10 (Ultraviolet-B: 10 min.), UVB20 (Ultraviolet-B: 20 min.), UVB40 (Ultraviolet-B: 40 min.) SDA (Storage duration average), $\operatorname{TrA}$ (Treatment average), *The different letters in line represent the significant differences among the storage duration at the level of $\mathrm{P}<0.05$, $* *$ The different letters in column represent the significant differences among the treatments at the level of $\mathrm{P}<0.05$ according to the Duncan test. 
Table 4. Green stalk rate, visual quality, decay rate, and taste scores of 0900 Ziraat cherry variety fruits during the storage $(\mathrm{mean} \pm \mathrm{SE})$.

\begin{tabular}{|c|c|c|c|c|c|c|c|c|c|}
\hline $\bar{C}$ & SD & $\bar{K}$ & KR & $\mathrm{M}$ & UVA & UVB10 & UVB20 & UVB40 & SDA* \\
\hline \multirow{7}{*}{ Green stalk rate } & 0 & $100.0 \pm 0.0$ & $100.0 \pm 0.0$ & $100.0 \pm 0.0$ & $100.0 \pm 0.0$ & $100.0 \pm 0.0$ & $100.0 \pm 0.0$ & $100.0 \pm 0.0$ & $100.0^{\mathrm{a}}$ \\
\hline & 7 & $83.3 \pm 15.3$ & $70.0 \pm 10.0$ & $86.7 \pm 15.3$ & $90.0 \pm 10.0$ & $83.3 \pm 5.8$ & $76.7 \pm 15.3$ & $70.0 \pm 10.0$ & $80.0^{\mathrm{b}}$ \\
\hline & 14 & $76.7 \pm 15.3$ & $86.7 \pm 11.5$ & $83.3 \pm 15.3$ & $73.3 \pm 15.3$ & $50.0 \pm 10.0$ & $83.3 \pm 15.3$ & $63.3 \pm 20.8$ & $73.0^{\mathrm{b}}$ \\
\hline & 21 & $73.3 \pm 23.1$ & $90.0 \pm 10.0$ & $86.7 \pm 11.5$ & $90.0 \pm 10.0$ & $63.3 \pm 5.8$ & $73.3 \pm 5.8$ & $56.7 \pm 15.3$ & $76.2^{\mathrm{b}}$ \\
\hline & 28 & $53.3 \pm 15.3$ & $43.3 \pm 15.3$ & $60.0 \pm 10.0$ & $70.0 \pm 10.0$ & $63.3 \pm 11.5$ & $50.0 \pm 0.0$ & $40.0 \pm 30.0$ & $54.3^{\mathrm{d}}$ \\
\hline & 35 & $30.0 \pm 10.0$ & $66.7 \pm 5.8$ & $86.7 \pm 5.8$ & $93.3 \pm 5.8$ & $36.7 \pm 47.3 \quad \delta$ & $83.3 \pm 15.3$ & $53.3 \pm 23.1$ & $64.3^{\mathrm{c}}$ \\
\hline & $\operatorname{TrA} * *$ & $69.4 b^{c d}$ & $76.1^{\mathrm{abc}}$ & $83.9^{\mathrm{a}}$ & $86.1^{\mathrm{a}}$ & $66.1^{\mathrm{cd}}$ & $77.8^{\mathrm{ab}}$ & $63.9^{\mathrm{d}}$ & \\
\hline \multirow{7}{*}{ Visual quality } & 0 & $5 \pm 0.0$ & $5 \pm 0.0$ & $5 \pm 0.0$ & $5 \pm 0.0$ & $5 \pm 0.0$ & $5 \pm 0.0$ & $5 \pm 0.0$ & $5.0^{\mathrm{a}}$ \\
\hline & 7 & $5 \pm 0.0$ & $5 \pm 0.0$ & $5 \pm 0.0$ & $5 \pm 0.0$ & $5 \pm 0.0$ & $5 \pm 0.0$ & $5 \pm 0.0$ & $5.0^{\mathrm{a}}$ \\
\hline & 14 & $5 \pm 0.0$ & $5 \pm 0.0$ & $5 \pm 0.0$ & $5 \pm 0.0$ & $5 \pm 0.0$ & $5 \pm 0.0$ & $5 \pm 0.0$ & $5.0^{\mathrm{a}}$ \\
\hline & 21 & $5 \pm 0.0$ & $5 \pm 0.0$ & $4.7 \pm 0.6$ & $4.7 \pm 0.6$ & $5 \pm 0.0$ & $4 \pm 0.0$ & $5 \pm 0.0$ & $4.7^{\mathrm{b}}$ \\
\hline & 28 & $3.7 \pm 0.6$ & $4.7 \pm 0.6$ & $4.3 \pm 0.6$ & $4.7 \pm 0.6$ & $5 \pm 0.0$ & $4 \pm 0.0$ & $5 \pm 0.0$ & $4.4^{\mathrm{c}}$ \\
\hline & 35 & $4 \pm 0.0$ & $3.7 \pm 0.6$ & $3.7 \pm 0.6$ & $3.7 \pm 0.6$ & $4 \pm 0.0$ & $4.7 \pm 0.6$ & $4.3 \pm 0.6$ & $4.0^{\mathrm{d}}$ \\
\hline & TrA** & $4.61^{\mathrm{c}}$ & $4.72^{\mathrm{abc}}$ & $4.61^{\mathrm{c}}$ & $4.67^{\mathrm{bc}}$ & $4.83^{\mathrm{ab}}$ & $4.61^{\mathrm{c}}$ & $4.89^{\mathrm{a}}$ & \\
\hline \multirow{7}{*}{ Decay rate $(\%)$} & 0 & $0.0 \pm 0.0$ & $0.0 \pm 0.0$ & $0.0 \pm 0.0$ & $0.0 \pm 0.0$ & $0.0 \pm 0.0$ & $0.0 \pm 0.0$ & $0.0 \pm 0.0$ & $0.00^{\mathrm{b}}$ \\
\hline & 7 & $0.0 \pm 0.0$ & $0.0 \pm 0.0$ & $0.0 \pm 0.0$ & $0.0 \pm 0.0$ & $0.0 \pm 0.0$ & $0.0 \pm 0.0$ & $0.0 \pm 0.0$ & $0.00^{\mathrm{b}}$ \\
\hline & 14 & $0.0 \pm 0.0$ & $0.0 \pm 0.0$ & $1.4 \pm 2.5$ & $1.4 \pm 2.5$ & $0.0 \pm 0.0$ & $0.0 \pm 0.0$ & $0.0 \pm 0.0$ & $0.40^{\mathrm{b}}$ \\
\hline & 21 & $8.3 \pm 6.6$ & $7.2 \pm 6.6$ & $1.6 \pm 2.7$ & $3.0 \pm 5.2$ & $0.0 \pm 0.0$ & $7.0 \pm 8.6$ & $0.0 \pm 0.0$ & $3.87^{\mathrm{a}}$ \\
\hline & 28 & $13.5 \pm 9.3$ & $4.4 \pm 4.5$ & $2.9 \pm 2.5$ & $6.9 \pm 2.1$ & $1.4 \pm 2.5$ & $2.9 \pm 5.0$ & $2.8 \pm 2.4$ & $4.96^{\mathrm{a}}$ \\
\hline & 35 & $2.7 \pm 4.6$ & $4.3 \pm 0.0$ & $4.1 \pm 4.2$ & $7.2 \pm 2.5$ & $7.5 \pm 3.0$ & $1.5 \pm 2.6$ & $5.5 \pm 4.8$ & $4.69^{\mathrm{a}}$ \\
\hline & $\operatorname{Tr} A^{* *}$ & $4.07^{\mathrm{a}}$ & $2.64^{\mathrm{ab}}$ & $1.67^{\mathrm{ab}}$ & $3.09^{\mathrm{ab}}$ & $1.48^{\mathrm{b}}$ & $1.90^{\mathrm{ab}}$ & $1.38^{\mathrm{b}}$ & \\
\hline \multirow{7}{*}{ Taste scores } & 0 & $5.0 \pm 0.0$ & $5.0 \pm 0.0$ & $5.0 \pm 0.0$ & $5.0 \pm 0.0$ & $5.0 \pm 0.0$ & $5.0 \pm 0.0$ & $5.0 \pm 0.0$ & $5.0^{\mathrm{a}}$ \\
\hline & 7 & $5.0 \pm 0.0$ & $5.0 \pm 0.0$ & $5.0 \pm 0.0$ & $5.0 \pm 0.0$ & $5.0 \pm 0.0$ & $5.0 \pm 0.0$ & $5.0 \pm 0.0$ & $5.0^{\mathrm{a}}$ \\
\hline & 14 & $4.9 \pm 0.1$ & $4.8 \pm 0.3$ & $4.9 \pm 0.1$ & $4.5 \pm 0.3$ & $4.7 \pm 0.6$ & $4.9 \pm 0.1$ & $4.7 \pm 0.2$ & $4.7^{\mathrm{b}}$ \\
\hline & 21 & $4.3 \pm 0.0$ & $3.9 \pm 0.8$ & $4.0 \pm 0.3$ & $4.1 \pm 0.2$ & $4.4 \pm 0.2$ & $4.5 \pm 0.4$ & $4.3 \pm 0.0$ & $4.2^{\mathrm{d}}$ \\
\hline & 28 & $4.6 \pm 0.5$ & $4.5 \pm 0.4$ & $4.5 \pm 0.4$ & $4.2 \pm 0.2$ & $4.4 \pm 0.5$ & $4.8 \pm 0.4$ & $4.5 \pm 0.4$ & $4.4^{\mathrm{c}}$ \\
\hline & 35 & $3.3 \pm 0.8$ & $3.5 \pm 0.5$ & $3.7 \pm 0.8$ & $4.0 \pm 0.5$ & $3.0 \pm 0.0$ & $3.7 \pm 0.3$ & $4.0 \pm 0.0$ & $3.5^{\mathrm{e}}$ \\
\hline & $\operatorname{Tr} \mathrm{A}^{* *}$ & \multicolumn{2}{|c|}{$4.51^{\mathrm{a}}$} & $4.44^{\mathrm{a}}$ & $4.51^{\mathrm{a}}$ & $4.42^{\mathrm{a}}$ & $4.63^{\mathrm{a}}$ & $4.58^{\mathrm{a}}$ & \\
\hline
\end{tabular}

C: Criteria, SD: Storage duration (days), K: Control, KR: Red LED, M: Blue LED, UVA: (Ultraviolet-A LED), UVB10 (Ultraviolet-B: 10 min.), UVB20 (Ultraviolet-B: $20 \mathrm{~min}$.), UVB40 (Ultraviolet-B: $40 \mathrm{~min}$.) SDA (Storage duration average), $\operatorname{TrA}$ (Treatment average), *The different letters in line represent the significant differences among the storage duration at the level of $\mathrm{P}<0.05$, **The different letters in column represent the significant differences among the treatments at the level of $\mathrm{P}<0.05$ according to the Duncan test.

\section{$L^{*}, a^{*}, b^{*}$, Hue Angle Colour Values}

$L^{*}$ colour values of cherry fruits increased in all treatments during storage compared to the initial level. However, the $L^{*}$ value of the fruits has been maintained the best both in $\mathrm{K}$ and $\mathrm{KR}$ (27.7) while the lowest values had in the UVB20 (26.4) treatment at the end of the experiment (Table 3). In the study, it determined that $L^{*}$ colour values mostly maintained in the UVA treatment during the storage period. The lowest colour $a^{*}$ values had obtained from UVB20 (15.9) treatment, and the highest one from UVA (21.8) application. In the experiment, it determined that changes in the $b^{*}$ colour value of cherries occurred in parallel with the colour $\mathrm{a}^{*}$ values. In the study, the highest hue angle value at the end of the storage period had observed in the cherry fruits in the $\mathrm{K}(15.04)$ group and the lowest value obtained in UVB20 (12.64) application (Table 3). The brightness of cherry fruits is a significant criterion for the consumer preference of the fruit as well as the fruit colour. The brightness of the fruit has formed by the cuticle or waxy layer on the fruit surface, which ensures the protection from external factors. During fruit development, significant changes occur wax and cutin content of cherry fruits, and since the accumulation of these components slows down in the early development period of the fruit, a thin cuticle layer forms on the fruit surface (Peschel et al., 2007). In the study, $L^{*}$ colour values varied according to the treatments but increased in all applications compared to the beginning of storage. Therefore, it has been observed that UVB and LED light treatments together with cold storage increase the brightness of the fruit. However, it had determined that the most effective treatments in increasing the brightness are UVB10 and UVA LED, whereas the application of UVB40 causes a decrease in brightness values. In the literature review, no previous study with the effect of UV-B and LED treatments on quality during cherry storage has encountered. However, Şen and Kuzucu (2016) stated that UV-C application in Regina variety cherries increases fruit brightness. In the current study, it has been found that low concentration UVB and UVA LED treatments led to increased brightness in cherries. Throughout the experiment, the colour $a^{*}$ and $b^{*}$ values of the fruits in UVB20 treatment found to be quite low compared to others, whereas the highest in UVA treatment. In the study, the highest hue angle found of the fruit in the control group while the fruit treated with UVB20 treatment has the lowest hue angle. According to these results, it understood that the colour of cherry fruits has darkened according to the beginning of the experiment due to aging. While the most change occurred in cherries treated with UVB20, the least change occurred in cherry fruits stored under UVA LED. In general, the colour change in cherry fruits was less in the ones stored under LED light than in the beginning, while it was more in the fruits stored after UV application. For this reason, it can say that ultraviolet light treatments have more effect on the colour increase than LED applications. However, UVB20 application was the most effective among the ultraviolet 
light applications performed at different doses. Wani et al. (2014) stated that cherry fruits lose their bright red colour after harvest, and the main reason for this is the breakdown of total or individual anthocyanins, along with other physiological and biochemical factors. In contrast, in the present study, it was found that UV-B and LED treatments improved the colour quality of cherries by increasing brightness, darkening red colour, and protection of anthocyanins.

\section{Electrolyte Leakage (EL, \%)}

Electrolyte leakage (EL) is the release of electrolytes from the cell due to deterioration of cell integrity as a result of physiological events such as chilling damage, physical damage, and radiation damage (Kasim and Kasim, 2016b). In the experiment, however, it had found that EL in all treatments decreased until 14th days of storage compared to the initial, whereas increased after this period (Figure 4). Besides, it has been observed that the most EL occurred in LED applied samples and followed by UVB applications. Therefore, it could say that UVB and LED applications increase EL in cherries. Although the storage of cherry fruits at low temperatures provides a decrease in EL for a certain period in all application groups, it has determined that there is a higher increase in all applications compared to the control group.

\section{Weight Loss (\%)}

In the study, it determined that the weight loss of cherry fruits in all treatments increased during storage, but this increase was at different levels among treatments (Figure $5)$. While the highest weight loss achieved in $\mathrm{K}(0.24 \%)$ application during storage, the lowest weight loss found in UVA $(0.13 \%)$ treatment. Since fruits and vegetables are alive after harvest, they continue their metabolic activities, and accordingly, quality losses occur. One of these quality losses is the decrease in the weight of the fruit due to water loss during storage. Weight losses can tolerate to a certain level, but after a certain threshold, it leads to a decrease in the marketable quality of the product. In the study, weight loss increased in all treatments during storage, while the most weight loss was in the control group and the least in the UVA treatment. Therefore, it might be possible that UVB and LED applications reduced weight losses. However, because weight loss varies only between 0.01 -
$0.52 \%$ during the trial period, it could be said that this weight loss will not cause a detrimental effect both on the visual quality of the fruit and decrease its marketable quality.

\section{Green Stalk Rate (\%), Visual Quality, Infection Rate} (\%), Taste scores

In the study, it determined that the green stalk ratio of cherries in the UVB40 treatment was the least $(63.88 \%)$, whereas the UVA application was more effective $(\mathrm{P}<0.05)$ in maintaining the green colour of the stalk $(86.11 \%)$. In the study, it observed that there was no loss in terms of visual quality in the first 14 days of the storage, and visual quality maintained at the same level as the initial quality in all treatment groups (Table 4). From this period to the end of the storage, it had found that, although there is a decrease in visual quality in all treatments, the UVB40 application maintains the visual quality better than other treatments $(\mathrm{P}<0.05)$. In the study, no decay was found until the 21 st day of storage in UVB10 and UVB40 applications, whereas it started on the 14th day in M and UVA treatments and the 21 st day in other applications (Table 4). However, according to treatments averages in Table 4, the highest decay rate has been observed in the $\mathrm{K}$ group $(4.7 \%)$, whereas the lowest one was in the UVB40 treatment (1.38\%). In the experiment, it had observed that the taste quality of cherries started to decrease as of the 14th day of the storage (Table 4), whereas the least taste change was in the application of UVB20 (4.6). Although the taste scores of other applications varied between 4.2-4.58. Preservation of the green colour of the fruit stem after harvest is an important quality criterion in cherry fruits. For this reason, it is also important that the post-harvest treatments to cherries must improve both the fruit quality and the green colour of the fruit stalk. In the present study, it had determined that UVB40 treatment caused darkening due to drying of the fruit stalk, whereas UVA treatment had found to be the most effective treatment to maintain the green colour of the stalk. It had determined that UVB applications are also very useful in maintaining visual quality and reducing the decay rate. In this study, although the taste quality of the fruits started to decrease as of the 14th day of the experiment, it was also found that it never fell below the three values that accepted as marketable quality limits.

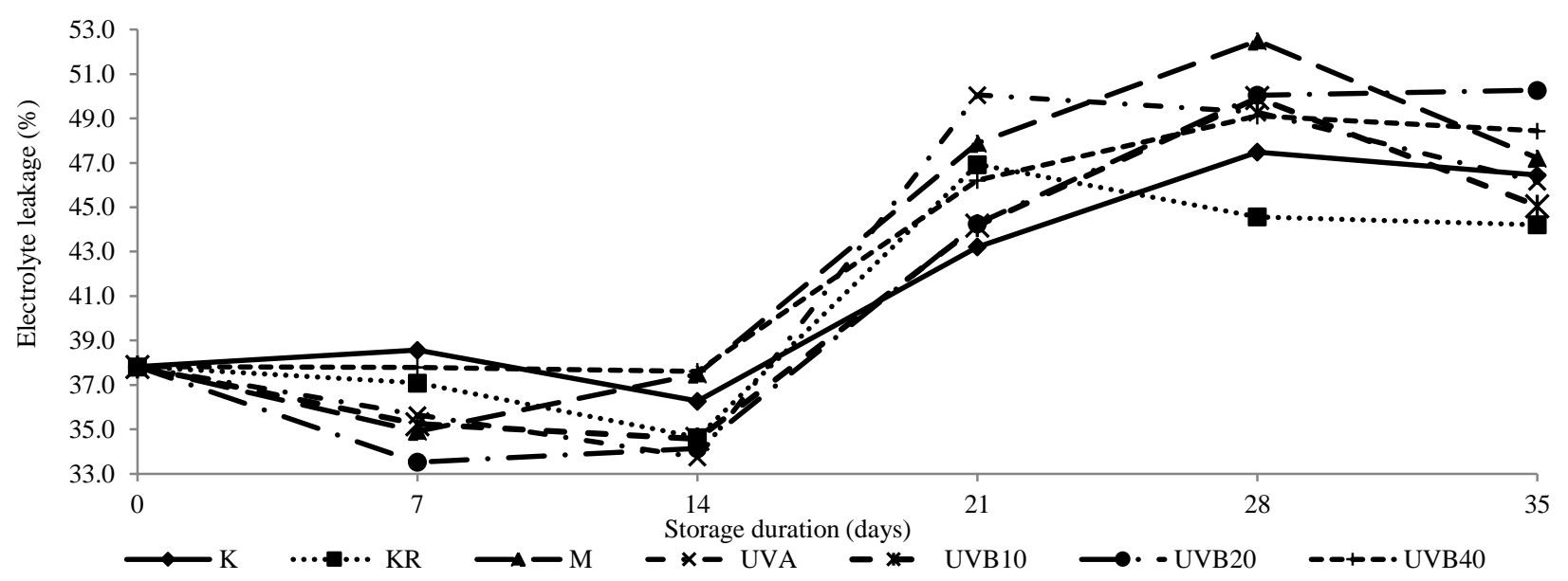

Figure 4. The changes of electrolyte leakage values of 0900 Ziraat cherry fruits during the storage 


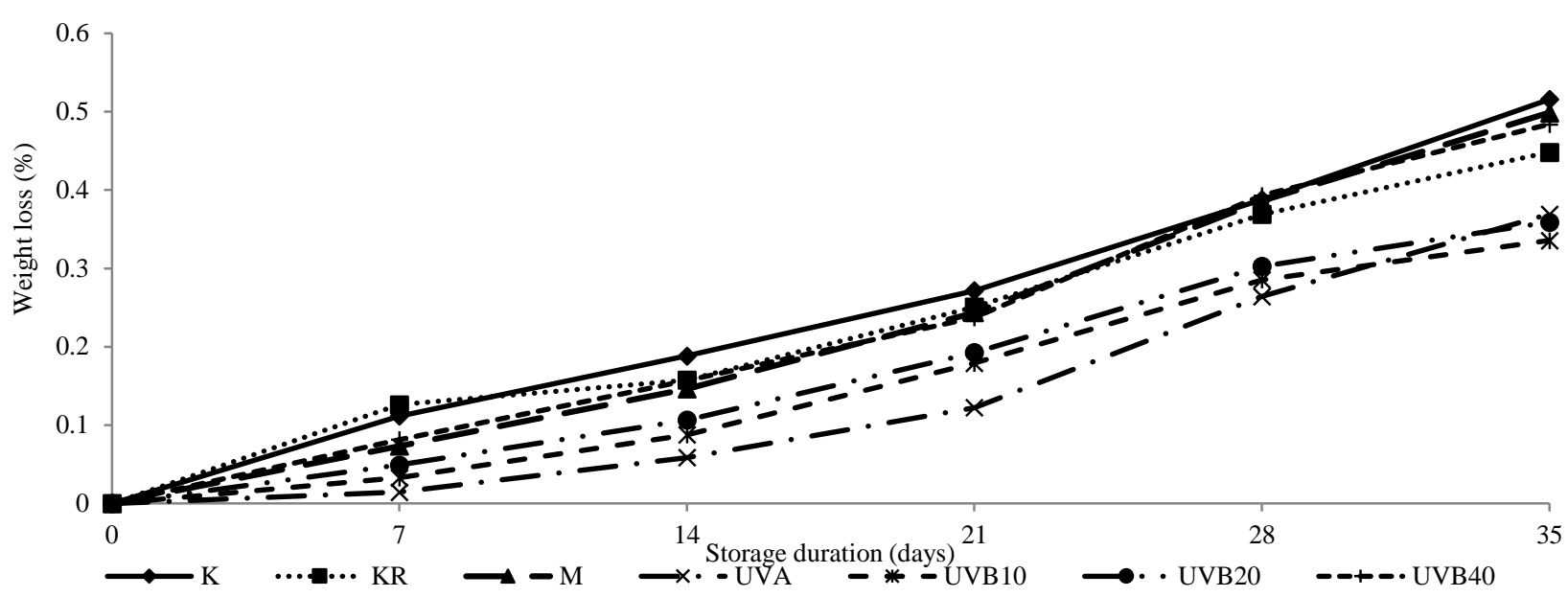

Figure 5. The changes in a weight loss of 0900 Ziraat cherry fruits during storage

\section{Conclusion}

In this study, the effects of three different doses of UVB as 10,20 , and $40 \mathrm{~min}$ with blue, red, and UV-A LED light treatments on the visual and biochemical quality of 0900 Ziraat cherries during storage had evaluated. According to all the results obtained in the study, it has found that ultraviolet-B treatments give better results in terms of the examined criteria than storage applications under the LED light. According to this, while UVB40 application stands out in terms of preserving fruit hardness and TSS content, UVB20 was the best application in terms of increasing titratable acidity, TSS/TA, glucose, and fructose content, and also taste quality. It was found that the best applications in terms of increasing the total soluble phenol and anthocyanin amounts are KR, UVB40, and UVB20, so the color of the fruits in these applications is better preserved than the others. The least weight losses have obtained in fruits in the UVA LED treatment, while this application also caused the fruit stalk to remain green. UVB10 and UVB40 treatments were effective in the disinfection of the fruit surface. As a result of the study, it has concluded that ultraviolet B treatments come to the fore, especially in terms of preserving the biochemical and visual quality of the fruit, and UVB20 is the best treatment among these applications. However, it has determined from the LED treatments that the red LED is better in increasing the total soluble phenol, and anthocyanin content whereas, UVA LED was the best in preserving the green color of the stalk.

\section{Acknowledgement}

We would like to thank Kocaeli University BAP Coordination Unit (Project No: 2017/096) for supporting this master's thesis study.

\section{References}

Anonymous, 2009. Simple Sugars: Fructose, Glucose and Sucrose. Available from: https://cdavies.wordpress.com/ 2009/01/27/simple-sugars-fructose-glucose-and-sucrose/ [Accessed 16 November 2018].

Crisosto C, Crisosto G, Metheney P. 2003. Consumer acceptance of 'Brooks' And 'Bing' cherries is mainly dependent on fruit SSC and visual skin color. Postharvest Biology and Technology, 28: 159-167. doi: https://doi.org/10.1016/S09 25- 5214(02)00173-4.
Çakırer G, Akan S, Demir K, Yanmaz R. 2017. Light Sources Used in Horticulture. Akademik Ziraat Dergisi (Academic Journal of Agriculture, University of Ordu), 6:63-70.

Çetinbaş M, Butar S, Koyuncu F. 2012. Effects of aminoethoxyvinylglycine (AVG) on fruit quality of 0900Ziraat sweet cherry. Ege Üniversitesi Ziraat Fakültesi Dergisi (Ege Journal of Agricultural Research), 49(1): 103-106.

FAOSTAT, 2020. Food and Agriculture Organization of the United Nations Available from: http://www.fao.org/faostat/ en/\#data/QC. [Accessed 20 October 2020].

Ferretti G, Bacchetti T, Belleggia G, Neri D. 2010. Cherry antioxidants: from farm to table. Molecules, 15(10):69937005. DOI: https://doi.org/10.3390/molecules15106993.

Genard M, Lescourret F, Gomez L, Habib R. 2003. Changes in fruit sugar concentrations in response to assimilate supply, metabolism and dilution: a modeling approach applied to peach fruit (Prunus persica). Tree Physiology, 23: 373-385. DOI: https://doi.org/10.1093/treephys/23.6.373.

Giusti MM, Wrolstad RE. 2001. Characterization and measurement of anthocyanins by UV-visible spectroscopy. Current Protocols in Food Analytical Chemistry, 1: F1-2.

Gonzalez-Aguilar A, Ruiz-Cruz S, Soto-Valdez H, Vazquez Ortiz F, Pacheco-Aguilar R, Wang C. 2005. Biochemical changes of fresh-cut pineapple slices treated with antibrowning agents. International Journal of Food Science and Technology, 40: 377-383. doi: https://doi.org/10.1111/j.13652621.2004.00940.x.

Kappel F, Fisher-Fleming B, Hogue E. 1996. Fruit characteristics and sensory attributes of an ideal sweet cherry. Hortscience, 31(3):443-446. doi: https://doi.org/10.21273/HORTSCI.31. 3.443.

Karaçalı İ. 2006. Storage and Marketing of Horticultural Products. Ege University, Faculty of Agriculture Publication, İzmir/Turkey, pp:445.

Kasım M, Kasim R. 2015. Postharvest UV-B Treatments increased fructose content of tomato (Solanum lycopersicon L. cv. Tayfun $\mathrm{F}_{1}$ ) harvested at different ripening stages. Food Science and Technology, Campinas, 35 (4): 742-749. doi: https://doi.org/10.1590/1678-457X.0008.

Kasim MU, Kasim R. 2016a. The effects of high dose citric acid treatments on polyphenol enzyme activity and quality of fresh-cut broad bean. Kahramanmaras Sutcu Imam University Journal of Agriculture and Nature Science, 19 (3):339-347.

Kasim M, Kasim R. 2016b. Effects of the different wavelength ultraviolet radiation on postharvest quality of fresh-cut spinach. Yuzuncu Yil University Journal of Agricultural Sciences, 26 (3):348-359. 
Kasım M, Kasım R. 2017a. While continuous white led lighting increases chlorophyll content (SPAD), green led light reduces the infection rate of lettuce during storage and shelf-life conditions. Journal of Food Processing and Preservation, E13266: 1-7. doi: https://doi.org/ 10.1111 /jfpp. 13266 .

Kasim R, Kasim MU. 2017b. The treatments of light emitting diode (LED) technology on fruit and vegetables during postharvest period. Fruit Science, 1(Special):86-93.

Koçak H, Bal E. 2017. Effects of postharvest UV-C and edible coating treatments on fruit quality and storage of sweet cherry. Turkish Journal of Agricultural Research, 4(1): 79-88. doi: https://doi.org/10.19159/tutad.300716.

Kurubaş M, Şahin Özalp G, Erkan M. 2017. Impact of modified atmosphere packaging on fruit quality and postharvest life of '0900 Ziraat' cherries. Derim, 35 (1): 19-26. doi: https://doi.org/10.16882 / derim.2018.314511.

Lancester JE, Lister CE, Reay PF, Triggs CM. 1997. Influence of pigment composition on skin color in a wide range of fruit and vegetables. Journal of the American Society for Horticultural Science, 122(4):594-598. doi: https://doi.org/ 10.21273/JASHS.122.4.594.

Mahmood T, Anwar F, Abbas M, Boyce M, Saari N. 2012. Compositional variation in sugars and organic acids at different maturity stages in selected small fruits from Pakistan. International Journal of Molecular Sciences, 13:1390-1392. doi: https://doi.org/10.3390/ijms13021380.

Mcguire RG. 1992. Reporting of objective color measurements. Hortscience, 27(12):1254-1255. doi: https://doi.org/10.212 73/HORTSCI.27.12.1254

Meheriuk M, Girar B, Moyls AL, Beveridge HJT, McKenzie DL, Harrison J, Weintrub S, Hocking R. 1995. Modified atmosphere packaging of 'Lapins' cherry. Food Research International, 28: 238-244. doi: https://doi.org/10.1016/09639969(95)00003-5.

Özçağıran R, Ünal A, Özeke E, İsfendiyaroğlu M. 2011. Temperate Fruit Species (Stone Fruits). Ege University, Faculty of Agriculture Publication, İzmir/Turkey.

Özkaya O, Șener A, Sarıdaş M, Ünal Ü, Validazeh A, Dündar Ö. 2015. Influence of fast cold chain and modified atmosphere packaging storage on postharvest quality of early season harvested sweet cherries. Journal of Food Processing and Preservation, 39: 2119-2128. doi: https://doi.org/10.1111/ jfpp. 12455.

Pala ÇU, Toklucu AK. 2010. Application of ultraviolet light UV technology to fruit juice processing. Akademik Gida (Academic Food Journal), 8(1):17-22.

Peschel S, Franke R, Schreiber L, Knoche M. 2007. Composition of the cuticle of developing sweet cherry fruit. Phytochemistry, 68 (7): 1017-1025. doi: https://doi.org/10. 1016/j.phytochem.2007.01.008.
Quero-García J, Schuster M, López-Ortega G, Charlot G. 2017. Sweet cherry varieties and improvement. In: Quero-García J, Lezzoni A, Pulawska J, Lang G (editors) Cherries Botany, Production and Uses. CAB International, Boston, ISBN 9781-7806-4837-8 (print), 978-1-7806-4839-2 (e-pub) pp:60-95.

Ribeiro C, Canada J. Alvarenga B. 2012. Prospects of UV radiation for application in postharvest technology. Emirates Journal of Food and Agriculture, 24 (6): 586-597. doi: https://doi.org/10.9755/ejfa.v24i6.14677.

San Martino L, Manavella D, Garcia D, Salato G. 2008. Phenology and fruit quality of nine sweet cherry cultivars in South Patagonia. Proc. $5^{\text {th }}$ Is on Cherry Acta Horticulturae, 795:S. 841848. doi: https://doi.org/10.17660/ActaHortic. 2008.795.136.

Spotts I, Sandhu R, Singh A, Collier C. 2017. Design of light emitting diode system for postharvest shelf-life enhancement of fresh produce. The Canadian Society for Bioengineering. CSBE/SCGAB Annual Conference Canada. pp:1-8.

Şen S, Kuzucu FC. 2016. Effect of different doses of UV-C on fruit quality and storage period on "Regina"e cherry cultivar. Çanakkale Onsekiz Mart Üniversitesi Ziraat Fakültesi Dergisi (COMU J. Agric. Fac.) 4(2):109-116.

Torçuk Aİ, Bal E, Gülcü M, Seçkin GU. 2016. Research the effect of the ethanol vapour on the cherry storage. Meyve Bilimi (Fruit Science), 1(Special):85-93.

TUIK, 2020. Türkiye İstatistik Kurumu. Available from: https://biruni.tuik.gov.tr/medas/?kn=92\&locale=tr. [Accessed 26 October 2020].

USDA, 2020. United States Department of Agriculture, FoodData Central. Available from: https://ndb.nal.usda.gov/ ndb/foods/show/2183 [Accessed 26 October 2020].

Usenik V, Fabčič J, Štampar F. 2008. Sugars, organic acids, phenolic composition and antioxidant activity of sweet cherry (Prunus avium L.). Food Chemistry, 107(1):185-192. doi: https://doi.org/10.1016/j.foodchem.2007.08.004.

Voća S, Dobričević N, Habun T, Čmelik Z, Družić J. 2008. Glucose, fructose and sucrose in the cherry fruits. Pomologia Croatica: Glasilo Hrvatskog agronomskog društva, 14(2): 93-100.

Wang Y, Long LE. 2014. Respiration and quality responses of sweet cherry to different atmospheres during cold storage and shipping. Postharvest Biology and Technology, 92: 62-69. doi: https://doi.org/10.1016/j.postharvbio.2014.01.003.

Wani AA, Singh P, Gul K, Wani MH, Langowski H. 2014. Sweet cherry (Prunus avium): critical factors affecting the composition and shelf life. Food Packaging and Shelf Life, 1(1): 86-99. DOI: https://doi.org/10.1016/j.fpsl.2014.01.005.

Yildirım A, Koyuncu F. 2010. The effect of gibberellic acid applications on the cracking rate and fruit quality in the ' 0900 ziraat' sweet cherry cultivar. African Journal of Biotechnology, 9 (38): 6307-6311. 